\title{
Correction to: Embrittlement Analysis of $\Sigma 5[210] /(-1-20)$ FeAl Grain Boundary in Presence of Defects: An Ab Initio Study
}

\author{
TOUKO LEHENKARI, S. ASSA ARAVINDH, WEI CAO, MATTI ALATALO, \\ MARKO HUTTULA, and JUKKA KOMI
}

https://doi.org/10.1007/s11661-021-06488-y

(C) The Author(s) 2021

Correction to: Metallurgical and Materials Transactions A https://doi.org/10.1007/s11661-021-06450-y

IN the original online version of this article, Touko Lehenkari's family name was misspelled. The original article has been corrected.

Publisher's Note Springer Nature remains neutral with regard to jurisdictional claims in published maps and institutional affiliations.

TOUKO LEHENKARI, WEI CAO, MATTI ALATALO, and MARKO HUTTULA are with the Nano and Molecular Systems Research Unit, University of Oulu, Penti Kaiteran Katu 1, Oulu, 90570, Finland. S. ASSA ARAVINDH is with the Nano and Molecular Systems Research Unit, University of Oulu and also with the Center for Advanced Steel Research, University of Oulu, Penti Kaiteran Katu 1, Oulu, 90570, Finland. Contact e-mail: Assa.Sasikaladevi@oulu.fi JUKKA KOMI is with the Center for Advanced Steel Research, University of Oulu.

The original article can be found online at https://doi.org/10.1007/ s11661-021-06450-y.

Article published online October 27, 2021 